\title{
Tackling the Global NCD Crisis: Innovations in Law and Governance
}

Bryan P. Thomas

Georgetown University Law Center, bpt11@law.georgetown.edu

Lawrence O. Gostin

Georgetown University Law Center, gostin@law.georgetown.edu

Georgetown Public Law and Legal Theory Research Paper No. 13-030

This paper can be downloaded free of charge from:

https://scholarship.law.georgetown.edu/facpub/1205

http://ssrn.com/abstract=2254944

41 J.L. Med. \& Ethics 16-27 (2013)

This open-access article is brought to you by the Georgetown Law Library. Posted with permission of the author. Follow this and additional works at: https://scholarship.law.georgetown.edu/facpub

Part of the Constitutional Law Commons, Diseases Commons, Health Law and Policy Commons, Health Policy Commons, Public Health Commons, and the Public Policy Commons 


\section{Tackling} the Global NCD Crisis: Innovations in Law and Governance

\author{
Bryan Thomas and \\ Lawrence O. Gostin
}

7 o someone holding a hammer, the cliché goes, everything looks like a nail. A similar myopia often afflicts legal minds as they approach deep-seated problems in global health, as every crisis is approached by first asking how it might be litigated away. In recent years, there has been a growing recognition of the limits of litigation as a tool for advancing equitable access to health - indeed of its potential, under some circumstances, to have a positively regressive impact. ${ }^{1}$ This very timely symposium offers us a chance to reflect more deeply on the matter.

Our aim in this paper is to draw the lens back from a narrow focus on litigation, to survey the broader landscape of global health law and governance. Many of the most pressing health challenges facing the world today are intertwined with the complex dynamics of globalization, and require policy solutions that see national and international institutions acting in concert, collaborating with the private sector and civil society. The most glaring and urgent case in point which will serve as the focal point of our discussion - concerns the precipitous rise of non-communicable diseases (NCDs) worldwide.

Four NCDs - cardiovascular disease, cancer, respiratory disease and diabetes - account for $63 \%$ of global deaths annually. The conventional wisdom, which conceives of NCDs as a 'First World' problem, is starkly belied by current data: of the 35 million people who die annually of NCDs, $80 \%$ are in low- and middle-income countries. The death toll is projected to rise by $17 \%$ over the next decade, unless meaningful steps are taken immediately. Recent meta-analysis of available data shows a quintupling of diabetes in rural areas of developing and middle-income countries. ${ }^{2}$ With the exception of Sub-Saharan Africa, NCD mortality now "exceeds that of communicable, maternal, perinatal, and nutritional conditions combined."3 Conventional wisdom errs as well in supposing that rising NCD rates are simply the byproduct of an aging population: more than $50 \%$ of its global burden strikes those under the age of 70 .

Beyond the immediate suffering and death represented by these numbers, NCDs take a toll on development, in rising health care costs and lost productivity. An authoritative study has estimated that the cumulative costs of NCDs will be at least $\$ 47$ trillion from

Bryan Thomas, S.J.D., is a Global Health Law Fellow, O'Neill Institute for National and Global Health Law, Georgetown University Law Center. Lawrence O. Gostin, J.D., LL.D., (Hon.), is University Professor and Faculty Director, O'Neill Institute for National and Global Health Law, Georgetown University Law Center; Director, World Health Organization Collaborating Center on Public Health Law and Human Rights. 
2010 through 2030, with mental illnesses accounting for more than one-third of the cost. This is a low-end estimate. Other economic models calculate the costs at far higher levels still. ${ }^{4}$ These costs manifest themselves in downward spirals of poverty, for individuals and families, as NCD sufferers find themselves unable to work, and faced with ruinous medical expenses.

groups, there is no cohesive, self-identifying group lobbying for action on all NCDs. Looking back at social mobilization against Big Tobacco, for example, one finds that the movement was driven by a core group of ardent volunteers - often relatives of the victims of tobacco-related illness. Political momentum around HIV/AIDS followed a similar dynamic. Rather than unify around a comprehensive strategy on NCDs, social movements have often splintered, raising consciousness about particular diseases.

The multifactorial causation of NCDs poses further challenges - not only for medicine and health policy, but also for social mobilization. As explained below, reducing the burden of NCDs will involve experimentation with various complementary strategies, across multiple sec-

The moral tragedy lies in the fact that this is largely preventable. The primary risk factors for NCDs are well known, and could be reduced or eliminated, given the political and social will - through aggressive tobacco control, reduced air pollution, healthier diets, increased physical activity, and reduced alcohol consumption. Together, these variables account for $80 \%$ of heart disease, stroke, and type 2 diabetes, and $40 \%$ of cancers. ${ }^{5}$

A problem as complex and consequential as NCDs requires engagement of national governments, the international community, and an "all-of-society" approach encompassing all key actors. Below we discuss innovative governance strategies at the national and international levels for addressing the problem of NCDs, spanning across various sectors (e.g., trade, agriculture, transportation, and the environment) and engaging diverse stakeholders (e.g., multilateral organizations, states, civil society, philanthropic groups, and industry). But before setting out in search of solutions, it is worth trying to understand the failings to date.

\section{The Quiet Growth of an Epidemic}

The past half-century has seen momentous accomplishments in global health: the triumph of polio vaccination, the eradication of smallpox, and unanticipated successes in containing the HIV/AIDS epidemic. On the face of it, the challenge of NCDs would appear comparatively manageable - as indicated, the risk factors are well understood, and there are promising strategies available to mitigate them. Why then has the problem been allowed to spiral out of control?

\section{Challenges in Social Mobilization around NCDs}

A key factor has been the lack of social mobilization, to date, pressing for urgent action. Though particular NCDs have heightened prevalence among specific tors. Whereas HIV/AIDS activists can rally around demands for access to anti-retroviral medicines, the policy demands of the anti-NCD movement will not fit neatly on a placard.

One might hope that litigation would serve as a catalyst for faltering social movements. Such was the case, for example, with the anti-tobacco movement in the U.S., as litigation led to the disclosure of damning industry documents, prompting public outrage and swift government action. A similar trajectory seems unlikely in the case of NCDs, in part because no single industry is to blame - the problems are manifold, as are the solutions. Typically, where NCDs give rise to litigation, claimants are seeking access to expensive medical therapies, such as cancer treatments. Rare are the cases where litigation is used to demand implementation of broad preventative strategies - though there have been encouraging developments around the issue of second-hand tobacco smoke. ${ }^{6}$

Plainly, the focus in addressing NCDs must be largely on prevention, as opposed to pharmacomedical treatment after the fact. But prevention strategies aimed at improved health for the next generation may lack the political urgency of treatment strategies that save identifiable lives today. Many of the strategies outlined below will pay out their dividends over decades. From the vantage point of today, the beneficiaries are largely statistical 'people' - e.g., the cohort of adults entering middle age, decades from now, experiencing reduced rates of adult-onset diabetes, thanks in part to public health interventions on diet and physical activity.

Moreover, prevention strategies often have a whiff of paternalism, and this can be a distinct political liability. New York City's Mayor recently unveiled plans to limit the serving size of sugary soft dinks sold in movie theatres and convenience stores, immediately earning 
himself the nickname 'Nanny Bloomberg.' Similarly, the anti-tobacco movement stalled for decades, as it was believed that the decision to smoke - by then known to be a life or death decision - was a matter of personal choice, not of public concern. It was only when the dangers of second-hand smoke came to light that the social movement gained momentum.

We mention these concerns about paternalism only to signal the drag they may have on social movements and, in turn, government action; in substance the concern is, quite frankly, often overblown. Like second-hand smoke, NCDs have an enormous impact on innocent third parties - among other things, by power worldwide. We mentioned some of these myths already: e.g., the view that NCDs affect only the elderly and the affluent; that they are the product of personal choice and therefore beyond the proper reach of government; and the fatalistic assumption that the problem is insolubly complex.

Moreover, even when NCDs are recognized as a problem, they are often placed below infectious diseases in decision makers' list of priorities. At the level of global institutions, this is partly a reflection of historical roles: the World Health Organization (WHO), and its institutional precursors in the late 19th and early 20 th centuries, were primarily focused on the

\section{The lack of social mobilization has allowed various myths about NCDs to go unchallenged in the halls of power worldwide. We mentioned some of these myths already: e.g., the view that NCDs affect only the elderly and the affluent; that they are the product of personal choice and therefore beyond the proper reach of government; and the fatalistic assumption that the problem is insolubly complex.}

using up scarce health care resources, increasingly in developing countries still burdened with deadly communicable diseases (the so-called 'double-burden'). Just as there is a valid public interest in assuring that citizens are educated and thereby able to contribute to the common good, so too there is a valid public interest in the prevention of chronic maladies.

Moreover, the anti-paternalism objection rests on a perverse assumption - namely, that the status quo, with its rising NCD rates, is itself the product of individual choices, freely made. ${ }^{7}$ The reality of course is that myriad collective decisions - made by governments and private interests - shape the menu of options available to individuals, determining the price and availability of nutritious foods, the accessibility of places to exercise, ways to commute to and from work, and so on. There is no avoiding government influence over risk behaviors. The question is only whether that influence will advance or detract from the ability to lead a healthy lifestyle. Calls for a laissez-faire approach are especially galling, given it is the poor who will bear the brunt of government inaction - as they may lack the financial means and leisure time needed to prepare healthy foods, exercise, have regular checkups, and so on.

\section{Misunderstanding among Key Decision Makers}

The lack of social mobilization has allowed various myths about NCDs to go unchallenged in the halls of containment of infectious diseases. Having specialized in infectious diseases for decades, WHO has been reticent in pressing an expanded agenda on the broader determinants of health. If the aim is to promote long and healthy lives, WHO's prioritization is quite misguided, as there is a direct interplay between infectious diseases and NCDs. Many infectious agents are known to cause cancer (e.g., HPV and cervical cancer); many of the risk factors for NCDs also exacerbate infectious diseases (e.g., smoking increases the risk of death from tuberculosis); and infectious disease therapies increase the risk of NCDs (e.g., antiretroviral regimens can increase the risk of heart disease in HIV patients). A recent study found that 1 in 6 cancers worldwide are caused by treatable or preventable infections. Infection-related cancers are much more prevalent in the developing world than the developed ( $23 \%$ of cancers versus $7 \%$, respectively) - owing to lack of vaccination and antimicrobial treatments, etc. ${ }^{8}$

Lastly, decision makers often assume that their pursuit of economic development will bring improved health as a byproduct. That assumption is tenuous in the case of NCDs, which may in fact be exacerbated by development, as urbanization leads to increased reliance on cars, less green space for recreation, and rising incomes lead to increased consumption of tobacco, alcohol, and calorie laden foods. Globalization of trade and investment - a favored strategy for economic 
development - facilitates the supply and marketing of unhealthy consumer goods.

The situation is dire but not hopeless. Given the political will, there is much that national governments can do to stem the tide on NCDs. As we will explore in section 2, the options range from soft interventions such as improved food labeling to more direct forms of regulation (e.g., banning trans fats). Yet efforts to respond to this crisis are doomed to fail without international cooperation. Many of the risk factors associated with NCDs are, in a very real sense, communicable. They are communicated from wealthy nations to developing nations, facilitated by global trade agreements, through the marketing and export of cigarettes, alcohol, and unhealthy processed foods. Billions of people worldwide have seen their physical, cultural, and nutritional landscape drastically changed in recent decades, by forces of globalization that lie mostly beyond their control. In section 3, we explore how global governance strategies might respond as a force for health.

Though we will focus largely on public institutions, one must recognize the essential role of the private sector in the search for sustainable solutions to the NCD epidemic. While the anti-tobacco movement rightly demands that Big Tobacco be denied any role in public health initiatives, the food industry will need to be engaged, on an ongoing basis, in the battle against NCDs. This need for ongoing food industry engagement, as part of lasting solution, remains a daunting challenge: experience with tobacco suggests that entrenched industries will fight reforms tooth-and-nail. In section 4, we explore the promise and perils of multisectoral solutions to the NCD crisis.

\section{Domestic Strategies for Addressing NCDs}

National governments - and their counterparts at the state and local level - will of necessity be the primary actors in the battle against NCDs, as they alone possess the sovereign authority to implement needed legal and regulatory measures. Indeed, under international human rights law, domestic governments are obligated to promote the highest attainable standard of health among their population, within the resources at their disposal. What does this obligation require, concretely, by way of action on NCDs? There is no one-size-fits-all governance solution, as interventions must be tailored to the particular needs of a population and optimized within resource constraints. In what follows, though, we survey some key interventions, ranging from simple surveillance of NCD rates to more direct, 'command and control' regulation. ${ }^{9}$
Monitoring Rates of NCDs

While infectious disease surveillance is well accepted, surveillance of chronic diseases remains, in some circles, controversial. ${ }^{10}$ For example, New York city has drawn controversy with its diabetes surveillance program, which includes mandatory laboratory reporting of glycated hemoglobin, directives for physicians in managing patients with poor glycemic control, and advice to patients about diabetes management. Civil libertarians and some physicians vehemently oppose surveillance, arguing it interferes with patient privacy, clinical freedom, and the doctor-patient relationship. Patients can opt out of receiving health department advice, but not the reporting requirement. However, opting out is a complex procedure, which itself requires limited information disclosure. ${ }^{11}$

Monitoring of NCD rates is essential if governments are to be held accountable for health outcomes among their populations. A purely 'opt-in' scheme for surveillance would run the risk of selection bias: if, for example, a given minority group is prone to opt-out, their rising NCD rates may go unnoticed. Moreover, as indicated, there is good reason to question the traditional outlook - seemingly at play in opposition to surveillance programs - which sees infectious diseases as a proper concern of public health officials, but non-communicable diseases as falling within the privity of patient/doctor relationships.

\section{Full Disclosure of the Health Effects \\ of Consumer Goods}

Consumers often make poor product choices because they lack clear, comprehensible information. Consider the bewildering way in which much food is marketed: "low fat" can mask for high sugar and sodium, "low sodium" can mask for high calorie; "zero trans fats" can mask for high saturated fats; and so forth.

To remedy this obfuscation, governments can compel industry to disclose the truth about their products, by requiring clearer food package labeling, health warnings on cigarettes and alcohol, and nutritional information on restaurant menus. The United Kingdom Food Standards Agency developed a voluntary system that is visible and simple to follow. Known as a "traffic light" system, companies must label foods with prominent green, yellow, or red lights for each of the major nutritional groups - whole grains, saturated fat, sodium, and sugar. ${ }^{12}$ Not only does this clearly inform the lay public, but it also provides an incentive for food manufacturers to develop healthier products, to avoid the stigma of four prominent red lights on their packaging. Uniform labeling across brands may in turn promote healthy competition - in the most literal sense. Happily, clear and comprehensible food 
labeling is entirely consonant with concerns for personal autonomy, as it merely enables individuals to make informed choices.

\section{Regulation of Advertisements}

Many governments have already limited advertising of cigarettes and alcoholic beverages, to forbid the targeting of children and adolescents (though in virtually every country, more could be done, for example, on plain packaging of cigarettes). The notable exception is the food industry, which alone spends more than $\$ 11$ billion annually to market its products in the United States alone. The bulk of industry spending is to promote unhealthy foods, such as sweetened beverages, sugary cereals, candy, and highly processed foods with added sugar, fats, and sodium. ${ }^{13}$ Advertising is ubiquitous, spanning television, radio, and the print media to the Internet and "advergames," where food is used as a lure in fun video games. ${ }^{14}$ The industry has adopted ineffectual voluntary self-regulatory measures..$^{15}$

In 1980, Québec, Canada banned fast food advertisements targeting children, which has reduced annual spending on fast foods by an estimated $\$ 88$ million. The province now boasts the country's lowest childhood obesity rate. Moreover, healthier eating habits, once ingrained in childhood, are carried into adult life. ${ }^{16}$

Regulating the content of advertising is contentious, potentially implicating constitutional rights to commercial free speech. Certainly the public supports regulation of misleading messages directed toward young people, yet there is bound to be disagreement over what messages are misleading versus simply alluring. Despite these concerns, regulation of advertising to children may be politically acceptable given the potential for manipulation of vulnerable youth and the state's responsibility to protect minors.

\section{Setting Incentives and Disincentives}

Government's main method of disincentivizing the purchase of certain products is to levy taxes on them. So-called 'fat-taxes' have been proposed as a proactive response to a food industry and consumer culture that increasingly promotes unhealthy foods as the cheapest, tastiest, and most readily accessible option. ${ }^{17}$ The World Health Organization has endorsed this strategy. ${ }^{18}$

As expected, critics allege that fat taxes are paternalistic, and also regressive, as poor people are the primary consumers of high-fat foods. Again, it is instructive to contrast this to the regulation of cigarettes, where there is greater support for state intervention. One rarely hears it argued that cigarette taxes are paternalistic - not in serious debate, at least - as it is widely acknowledged that they serve merely to internalize the full social costs of smoking. On the 'regressive' charge, notice that cigarette taxes are often praised as having a progressive health impact, precisely because the deterrent effect becomes stronger as one moves down the income scale. ${ }^{19}$ In the case of cigarettes there are valid concerns that heavy taxation may lead to smuggling and black market sales, particularly in the developing world; ${ }^{20}$ the Framework Convention on Tobacco Control, discussed below, is meant partly to address this problem. ${ }^{21}$

Unlike cigarettes - for which cessation is the best option - government can take steps to incentivize the production, sale and consumption of healthier foods, for example, by subsidizing fresh fruits and vegetables at the level of the farm or retailer. (In some leading food producing states, a first step would be to cease the subsidization of unhealthy foods, such as high fructose corn syrup or cane sugar).

Furthermore, government, employers, and others could offer incentives for physical activity and exercise: subsidies for taking public transportation, joining fitness clubs, and participating in organized sporting activities. Tax policy can be used, for example, to provide individuals a "flexible spending account" of tax-exempt funds for physical activities or exercise, such as riding a bicycle to work or school.

\section{Direct Regulation}

A more aggressive, and controversial, approach to regulation would consist of an outright ban on foods or ingredients deemed to be especially injurious to health. A growing body of scientific evidence links trans fatty acids to coronary heart disease. The Institute of Medicine concluded that trans fats provide no benefit to human health, and that there is no safe level of trans fat consumption. ${ }^{22}$ In 2003, Denmark became the first country to set an upper limit on the percentage of industrially produced trans fat in foods. New York City later restricted the sale of products containing artificial trans fat in all restaurants. As of July 1, 2007, restaurants were prohibited from preparing recipes that contain more than $0.5 \mathrm{~g}$ of trans fat per serving. ${ }^{23}$ The Food and Drug Administration, moreover, requires trans fat levels to appear on food labels. Notice, however, that even $0.5 \mathrm{~g}$ of trans fat per serving is unhealthy, especially if a consumer is eating multiple servings during the course of a day. Recent studies have shown the New York ban to be a clear success - restaurants have lowered trans fat levels without raising prices or substituting a commensurate rise in saturated fats. ${ }^{24}$

Incremental forms of direct regulation have been proposed as 'end game' strategies in the war against 
tobacco. Some propose gradually reducing the nicotine content of cigarettes, eventually dropping below the threshold levels of addiction. ${ }^{25}$ Others propose a 'sinking lid' on the supply of cigarettes available for commercial sale, ${ }^{26}$ or grandfathering schemes that peg the age of sale to a calendar year - e.g., permanently prohibiting the sale of cigarettes to anyone born after January 1, 2000. ${ }^{27}$

\section{Performance-Based Regulation}

There is a concern that direct 'command and control' methods of regulation may have unforeseen negative community. In this way, public health goals are closely aligned with goals of the environmental movement. Finally, governments could require that planning for new developments include health impact assessments. Consultation with communities and public health evaluations could be required as a pre-condition of initiating significant building projects.

This survey of regulatory options available to domestic governments is necessarily cursory. Individual countries and communities will need to choose among these and other options, developing strategies that address their needs. What we mean to impress

Individual choices are not made in isolation, but reflect in important ways the environment in which people live. The built environment may facilitate or inhibit a healthy lifestyle. Government's job is to make health the easier, or default, choice rather than, at present, the much more difficult choice. Government can work to help people stay healthy by enacting zoning and land-use laws that create healthier places for its residents to live.

consequences; the approach puts great stock in government's ability to engineer healthy lifestyles. An alternative approach, which gets around this problem, is for government to set a measurable outcome, which companies must reach within a certain period of time, or face penalty. ${ }^{28}$ It is then left to relevant food companies to figure out a way to meet these targets at pain of penalty if they fail. This approach harnesses the private sector's capacity for innovation as an engine of public health.

\section{Optimize the Built Environment for Health}

Individual choices are not made in isolation, but reflect in important ways the environment in which people live. The built environment may facilitate or inhibit a healthy lifestyle. Government's job is to make health the easier, or default, choice rather than, at present, the much more difficult choice. Government can work to help people stay healthy by enacting zoning and land-use laws that create healthier places for its residents to live. By designing green spaces, playgrounds, sidewalks, and paths for easy walking, hiking, and biking, local government can do a great deal to improve the health of the population.

Government can also take steps to limit or discourage motor vehicles in city centers, to encourage pedestrian traffic and make the air cleaner for walkers and bicyclists. Thus, supporting mass transit systems and ensuring safe routes for people to walk to school, work, and shops are an essential part of a healthy is simply the breadth of options available to governments - hopefully giving readers some sense, by implication, of the limited role for courts.

We next explore how governance structures at the international level could support national governments in their efforts to combat NCDs. The question links to an innovative global civil society project recently launched, pressing for a Framework Convention on Global Health.

\section{Marshaling a Global Response}

For a time, rising NCD rates were met with apathy from the global community. There is no global fund for chronic diseases, no major foundation championing the cause, little mention by the G8 or G20, and the issue is not even targeted in the UN's Millennium Development Goals. As discussed, the preeminent global health institution, WHO, has historically focused its attention and resources on infectious diseases - though that is changing, as we will explain.

The complexity of NCDs presents a challenge in forging a unified and comprehensive global response. NCDs comprise a basket of various diseases, implicating risk factors that span multiple sectors of economies and societies. Furthermore, viable solutions will necessarily implicate not only public actors but also a host of private actors, including private companies, civil society, the media, and academia. We begin by explaining why a global response is needed, notwithstanding these formidable challenges. 
Why a Global Response Is Urgently Needed

Processes of globalization have led to a harmonization of behaviors - exacerbating many of the risk factors for NCDs in the process. ${ }^{29}$ Thus, for example, the industrialization of food manufacture, along with the globalization of trade in food, has led to the displacement of traditional diets, in favor of a dietary convergence around processed, high-sugar, high-salt, high-fat foods (HSSF foods). ${ }^{30}$ The health effects are exacerbated by urbanization, often linked to increased reliance on cars, polluted air, and fewer options for physical exercise.

Globalization also shapes the power dynamics in health politics, as large multinationals exert their influence, resisting change at every turn. Over the past quarter century, transnational tobacco companies have aggressively exploited growth opportunities in developing countries. ${ }^{31}$ Internet commerce, online marketing and the illicit trade in tobacco products have greatly complicated attempts to regulate the supply and marketing of these products. ${ }^{32}$ A strong correlation has been found between free trade liberalization and increased consumption of tobacco. ${ }^{33}$

After tobacco use, alcohol consumption is the world's third-largest risk factor for health burden; in middle-income countries, which constitute almost half of the world's population, it in fact poses the greatest risk. ${ }^{34}$ The alcohol industry is as globalized as the tobacco industry - creating comparable problems for regulation at the national level..$^{35}$ The industry also jealously defends its right to market its products, even portraying them as sexy, adventurous, and sporty.

The food industry is more complex given that food is part of life's necessities. But that industry too has ubiquitously marketed foods that are highly processed, fat laden, sweetened, and full of sodium.

Many lower income countries lack the resources needed to contain the risk factors associated with NCDs. ${ }^{36}$ Major multinationals promoting cigarettes, alcohol, and unhealthy foods may have resources at their disposal that far surpass the GDP of some of these countries. A global response is needed to ensure adequate resources, and to ensure that all countries have access to the necessary expertise.

\section{The Political Declaration on NCDs}

In recent years, WHO has begun to take initiative on the NCD pandemic, even if very late and too little. Arguably the most significant step was the adoption, in 2003, of the Framework Convention on Tobacco Control (FCTC), ${ }^{37}$ which provides a blueprint for national tobacco control policies, tying these to an evolving scheme of international protocols (e.g. controlling sales to minors, tobacco smuggling, and packaging guidelines). The FCTC was groundbreaking, being the first treaty negotiated under the auspices of the WHO. It is also one of the most widely embraced treaties in the history of the UN, having now 174 signatories.

Other WHO initiatives - which due to space constraints we can only mention here - include the Global Strategy for the Prevention and Control of Noncommunicable Diseases (2000), the Global Strategy on Diet, Physical Activity and Health (2008); the Global Strategy to Reduce the Harmful Use of Alcohol (2010), and the formation of a Global Noncommunicable Disease Network (NCDnet). ${ }^{38}$ The WHO is also formally linked to the Global Alliance for the Prevention of Obesity and Related Chronic Diseases - a grouping a NGOs working to coordinate strategies on diet and excercise. ${ }^{39}$

These various WHO initiatives, while important, did not bring the issue of NCDs to the same high profile as, for example, the global initiative around HIV/ AIDS. The global health community lobbied successfully for a High-level Meeting (HLM) of the UN General Assembly on the Prevention and Control of NCDs, which was held in September 2011. Hopes were understandably high: prior to this, there had only been one such meeting with a health focus - a momentous 2001 meeting on AIDS, which galvanized social and political action on that pandemic.

The HLM on NCDs resulted in the unanimous adoption of a Political Declaration on the Prevention and Control of Non-Communicable Diseases - a 65-point document, cataloguing many facets of the problem, and calling for a 'whole-of-government' and 'whole-of-society' response. ${ }^{40}$ Broadly speaking, the Declaration calls for a range of preventative measures, strengthening national health systems to ensure early detection and treatment of NCDs; international cooperation on NCDs; research and development; and monitoring and evaluation of progress on the issue.

The Declaration, however, is short on specifics for implementation, calling on member states to develop their own national action plans by 2013, guided by voluntary targets subsequently issued by the WHO in 2012. In May of 2012, the World Health Assembly - the voting body of WHO - gaveled through a resolution setting a global target of a $25 \%$ reduction in premature mortality from NCDs by 2025 (conveniently yielding a catchy slogan - "25 by 25 "). Setting very broad and distant targets in this way is the easy part, of course, as experience with climate change has shown; the hard part is establishing specific, near term targets, monitoring progress against clear benchmarks, and ensuring compliance. At the time of writing, member states were slated to meet by the 
end of October 2012 to establish further targets and a monitoring framework.

We emphasize that these are all voluntary, nonbinding targets - a feature which has been the focus of many critiques of the Declaration. UN Special Rapporteur on the Right to Food, Olivier De Schutter, for example, promptly complained of a missed opportunity for firm action to end farm subsidies for nonnutritious foods, or to curtail the marketing of junk food to children worldwide. ${ }^{41}$ Similar complaints have issued from advocacy groups working on other NCD risk factors. What was conspicuously absent from the Political Declaration were effective measures for global governance - either "soft" or "hard" - with the power to steer global health action on NCDs.

It is unfortunate that this important groundwork for global action on NCDs was laid during a severe economic downturn. Though the Declaration recognizes the need for resources, it makes no commitments to provide them - instead calling on Member States to investigate funding options, within their budget allocations, and through 'innovating financing mechanisms.' The Declaration speaks as well of the importance of North-South cooperation, but takes no steps to set that in motion.

Ambitious, long-term targets and catchy slogans can play an important role in consciousness raising the campaign to eradicate smallpox worked to a target date, and more recently the ' 3 by 5 ' slogan (three million people on antiretroviral therapy by 2005) was an inspiring benchmark for the HIV/AIDS movement. However, the ' 25 by 25 ' target is ambitious even by comparison to those lofty campaigns, and there is no agreement on intermediary benchmarks.

The challenge grows more daunting by the day, as key risk factors of smoking, alcohol, unhealthy diet, and insufficient physical exercise are on the rise, as is the primary risk factor - aging. Moreover, there are limits on what can be achieved through preventative measures in the space of 13 years. A good portion of the target $25 \%$ reduction will need to be achieved through treatment rather than prevention - requiring dramatic increases in funding, full engagement of pharmaceutical companies, low cost and effective diagnostics, and buy-in from ministries of finance, trade, customs, and transportations. In contrast, curbing the NCD pandemic in the long run will require determined action to prevent the primary behavioral risk factors.

The Political Declaration will hopefully not be the last global pronouncement on the matter. Other ambitious ideas have been tabled for global health governance, some building on the framework convention model employed for tobacco control. For example, there is a growing campaign afoot for a Framework Convention on Global Health (FCGH), building on the precedent of the historic FCTC. The Joint Action and Learning Initiative on National and Global Responsibilities for Health (www.jalihealth.org) is leading this campaign, which aims to broadly reshape global governance for health - establishing binding national and international commitments on health, addressing many of the key risk factors for NCDs. ${ }^{42}$ Borrowing from the FCTC or FCGH, advocates have called for a framework convention on alcohol and on obesity itself.

\section{Challenges to a Global Response}

The WHO, unlike any other global-health body, can create legally binding conventions, requiring a twothirds majority vote by member states. However, the WHO has generally preferred to issue non-binding recommendations, guidelines, and standards. Lack of political will has often stood in the way. An example is the attempt to adopt a binding regulation on the marketing of breast-milk substitutes, dating back to the 1970s, which failed thanks to opposition from some developed countries. ${ }^{43}$

The WHO's reluctance to use hard legal instruments has been lamented by some. ${ }^{44}$ Others argue that the direct costs associated with drafting, ratification, and enforcement of international laws - together with disadvantages of prioritizing process over outcomes, consensus over diversity, generality over specificity, states over non-state actors, and lawyers over health researchers - make the soft law approach a better option. $^{45}$

Most importantly, for any approach that is adopted there must be mechanisms to ensure compliance. This is true for both hard and soft law. The risks here are evidenced with the FCTC: despite this legally binding instrument, tobacco use is increasing in many poor countries, and remains the second-largest cause of disease risk in middle-income countries. ${ }^{46}$

\section{Multisectoral Approaches: Their Promise and Pitfalls}

Our discussion to this point has advocated an 'all-ofgovernment' approach, encompassing a range of policy initiatives that fall outside the health portfolio as traditionally conceived - implicating trade, agriculture, urban planning, schools, the environment, etc. We then explained that the support and collaboration of global institutions was needed, to ensure that health is prioritized amidst global forces pursuing trade and economic development. In this final section, we look beyond the role of national and international public institutions, to explore the role of private companies, 
civil society, the media, and academia, in an 'all-ofsociety' effort to reverse NCD rates.

\section{Engaging Private Industry}

One can scarcely overstate the power that multinationals wield over the risk factors associated with NCDs, from the labeling and nutritional content of foods on grocery store shelves and in restaurants, to the global marketing of sugary drinks, alcoholic beverages, and cigarettes. If the pandemic is to be dealt with, private industry must play some role. It can be compellingly argued that the tobacco industry has no role to play multinationals, with deep pockets and demonstrated lobbying savvy. As we've seen, the counterbalancing forces of social mobilization on this issue have, to date, been fragmented and ineffectual - due in part to inherent features of the NCD crisis (e.g., the diversity and complexity of ailments captured by this umbrella term).

Problems akin to regulatory capture can arise whether private industry is regulated under a command-and-control model, or instead engaged in public-private partnerships. As others have noted, the ofttouted model of 'public-private partnerships' is poorly defined and multiply ambiguous. In some instances, the ostensible 'partners' are tied only financially, with the private sector funding government initiatives (or vice versa). In other cases, partnerships merely provide a forum for 'discussion' between public and private sectors, with no money changing hands, and no shared governance responsibilities. In other cases still, partnerships involve more formal governance structures, with voting boards drawn from public and private

as a partner in public health, as that industry will best contribute to public health by disappearing. The same cannot be said, though, of the food industry - nor, realistically, of the alcohol industry.

The question is not so much whether private industry will be engaged, but how. And public health agencies - both domestic and global - must adopt clear conflict of interest rules that prevent industry from having preferential access to policymaking or undue influence. Various arrangements are possible, ranging from command-and-control approaches to public/ private partnerships, through to voluntary self-regulation. No prescription can be issued in the abstract; a dynamic approach is needed, driven by the pursuit of the public's health. We offer some pathways for constructive industry engagement.

There are well-known risks involved in attempting to regulate well-entrenched private industries. Among these is the risk of regulatory 'capture,' whereby public agencies fall under the sway of industries under their charge. The theory here, roughly stated, is that subjects of regulation have a high-stakes interest in influencing their regulators, and will focus their energies and resources to sway policy in a favorable direction. Even if raw self-interest does not hold sway, regulators and industry work so closely with one another that they can get too cozy and comfortable. On the face of it, the risk of regulatory capture seems especially acute in efforts to address NCD risk factors. The food, alcohol, and cigarette industries are dominated by huge sectors. ${ }^{47}$ And these partnerships can delay or even block what may be truly needed, which is direct regulation. One cannot assume that these partnerships are structured to serve the public interest; they must be carefully scrutinized to guard against conflicts of interest.

There will often be no path of 'enlightened selfinterest' leading major multinationals to voluntarily sell healthier goods. The reality, as one author puts it, "is that 'good' foods are bad commodities with low profit margins while 'bad' foods are good commodities." 48 The public health community must brace itself for a long, uphill battle on this issue, and be very wary of 'win-win' solutions touted by industry. Ultimately, it must become unacceptable for industry to aggressively market unhealthy products, enticing consumers to eat food or drink beverages that are distinctly unhealthy.

\section{Civil Society Engagement}

In its political dynamics, the issue of NCDs has a foreboding similarity to climate change: both involve urgent global challenges, requiring major investments of financial resources and political capital, whose dividends will pay out long after the next election cycle. Under these circumstances there is a strong temptation for those in positions of power - in government and private industry - to leave the problem for another day. It therefore falls to civil society to be vocal and relentless on this issue, pressing governments to 
set out detailed strategies, with near-term benchmarks and monitoring requirements.

Here too, one must demand transparency from civil society groups, and be watchful for potential conflicts of interest. As with every dirty trick in health politics, this one has been performed par excellence by the tobacco industry, which for decades disseminated misinformation about the health risks and addictiveness of cigarettes, through front groups masquerading as independent think tanks. ${ }^{49}$

Broader consciousness-raising about NCDs will be vital as well - pitched at the general public qua citizens and consumers. In the current climate of worldwide government austerity, it will no doubt be argued that the problem is too costly to address now; this attitude dovetails ideologically with the view that NCD prevention is a matter of personal rather than public responsibility. Public initiatives to address the tobacco and HIV/AIDS epidemics were stalled for a time, with enormous human costs, thanks to misguided beliefs along these same lines. The point needs to be driven home relentlessly that government can respond effectively to the NCD crisis, and that failure to do so will be many times more costly.

Having secured a place for NCDs on the public agenda, civil society will then have an ongoing role to play, lending its expertise to the development and selection of evidence-based policy responses. ${ }^{50}$ As the survey of policy options above suggests, expert input from very diverse sources will be required (e.g., experts in urban planning, agriculture policy, and information sciences).

Through all of this, global cooperation among civil society groups will be essential. The coming years will hopefully see experimentation with novel strategies to reverse NCD rates, offering an opportunity for countries to learn from one another's successes and failures. Civil society groups will have an important role to play in this learning process, as impartial observers committed to advancing public health.

\section{Why the Crushing and Unequal Burden of NCDs Is Unacceptable}

It seems paradoxical, on its face: the major health challenges of our time desperately call out for national and global action on an unprecedented scale; yet the trend in many countries is toward litigation of health rights, often on an individualized basis. On reflection, though, it appears that these two trends may be mutually supporting. Our failure to take meaningful, collective action to reverse rising NCD rates has left health systems worldwide to cope with the burden. As those systems reach their resource capacity, there is no choice but to ration care. The end result: worldwide, vast numbers of very sick people coping with chronic illnesses, scrabbling for expensive treatments; those who can appeal to the courts as a last resort.

The NCD crisis is largely of our own making reflecting individual and societal choices - and can be reversed only through concerted national and global effort. The past century has seen inspiring achievements in public health, though perhaps none has required such a broad, multi-sectoral response as reversing the dominant trend of ever increasing obesity, sedentary lifestyles, and self-destructive behavior through tobacco use and excessive consumption of alcoholic beverages.

For those who argue that all this suffering and economic toll is only a matter of personal choice, family responsibility, and the free market, we insist that the status quo is simply unacceptable. Make health the easier, default, option, rather than being agonizingly difficult. ${ }^{51}$ Reveal the suffering of people, families, and whole societies caused by the crushing burden of NCDs. And refuse to accept the unconscionable health inequalities between the rich and poor - both within and among nations.

\section{Acknowledgements}

The authors would like to thank Anna Garsia, Dina Jerebitski, Thandiwe Lyle and Corey Kestenberg for their assistance in the preparation of this article. This article reflects ideas in Professor Gostin's forthcoming book, Global Health Law: International Law, Global Institutions, and World Health (Harvard University Press, forthcoming 2013).

\section{References}

1. O. L. M. Ferraz, "Harming the Poor Through Social Rights Litigation: Lessons from Brazil," Texas Law Review 89, no. 7 (2011): 1643-1668; C. M. Flood and B. Chen, "Charter Rights \& Health Care Funding: A Typology of Canadian Health Rights Litigation," Annals of Health Law 19, no. 3 (2010): 479-526. There are broader, more longstanding critiques of rights as a mechanism for progressive political change; see generally, Wendy Brown \& Janet Halley, eds., Left Legalism/Left Critique (Durham: Duke University Press, 2002).

2. C. K. Wang et al., "Rural Diabetes Prevalence Quintuples Over Twenty-Five Years in Low- and Middle-Income Countries: A Systematic Review and Meta-Analysis," Diabetes Research and Clinical Practice 96, no. 3 (2012): 271-285.

3. World Health Organization, Global Status Report on Noncommunicable Diseases 2010 (Geneva: WHO, 2011).

4. D. E. Bloom et al., The Global Economic Burden of Non-Communicable Diseases, A Report by the World Economic Forum and the Harvard School of Public Health (Geneva: World Economic Forum, 2011): at 27, 29.

5. World Health Organization, Preventing Chronic Diseases: A Vital Investment, WHO GLOBAL REPORT (Geneva: WHO, 2005).

6. See O. Cabrera and J. Carballo in this issue.

7. L. O. Gostin and K. G. Gostin, "A Broader Liberty: JS Mill, Paternalism, and the Public's Health," Public Health 123, no. 3 (2009): 214-222.

8. C. de Martel et al., "Global Burden of Cancers Attributable to Infections in 2008: A Review and Synthetic Analysis," Lancet Oncology 13, no. 6 (2012): 607-615. 
9. L. O. Gostin, Public Health Law: Power, Duty, Restraint, $2 \mathrm{~d}$ ed. (Berkeley: University of California Press, 2008).

10. R. A. Epstein, "What (Not) to Do About Obesity: a Moderate Aristotelian Answer," Georgetown Law Journal 93, no. 4 (2005): 1361-1386.

11. T. R. Frieden, "Asleep at the Switch: Local Public Health and Chronic Disease," American Journal of Public Health 94, no. 12 (2004): 2059-2061.

12. Food Standards Agency, Traffic Light Labeling, available at <http://www.eatwell.gov.uk/foodlabels/trafficlights/> (last visited February 22, 2013).

13. Institute of Medicine, Food Marketing to Children and Youth: Threat or Opportunity? (2006): at 169, available at <http:// iom.edu/CMS/3788/21939/31330.aspx> (last visited February 22, 2013).

14. C. Hawkes, "Regulating Food Marketing to Young People Worldwide: Trends and Policy Drivers," American Journal of Public Health 97, no. 11 (2007): 1962-1973.

15. Children's Advertising Review Unit, Self-Regulatory Program for Children's Advertising, 9th ed. (Better Business Bureaus, 2009), available at <http://www.caru.org/guidelines/guidelines.pdf $>$ (last visited February 22, 2013).

16. T. Dhar and K. Baylis, "Fast-Food Consumption and the Ban on Advertising Targeting Children: The Quebec Experience," Journal of Marketing Research 48, no. 5 (2011): 799-813.

17. M. F. Jacobson and K. D. Brownell, "Small Taxes on Soft Drinks and Snack Foods to Promote Health," American Journal of Public Health 90, no. 6 (2000): 854-857.

18. Frequently Asked Questions About the WHO Global Strategy on Diet, Physical Activity and Health, World Health Organization Website, available at <http://www.who.int/dietphysicalactivity/faq/en/index.html > (last visited February 22, 2013).

19. K. E. Warner and D. Mendez, "Tobacco Control Policy in Developed Countries: Yesterday, Today, and Tomorrow," Nicotine $\mathcal{E}^{\circ}$ Tobacco Research 12, no. 9 (2010): 876-887.

20.Denis Campbell, "Developing World Faces Black Market Cigarette Plague," Observer, June 27, 2009.

21. L. Joossens and M. Raw, "From Cigarette Smuggling to Illicit Tobacco Trade," Tobacco Control 21, no. 2 (2012): 230-234.

22. Institute of Medicine, Dietary Reference Intakes for Energy, Carbohydrate, Fiber, Fat, Fatty Acids, Cholesterol, Protein, and Amino Acids (Washington, DC: National Academies Press, 2005).

23. "Notice of Adoption of an Amendment (\$81.08) to Article 81 of the New York City Health Code," New York City Department of Health and Mental Hygiene Board of Health Website, available at <http://www.nyc.gov/html/doh/downloads/pdf/public/ notice-adoption-hc-art81-08.pdf> (last visited February 22, 2013).

24. S. Y. Angell et al., "Cholesterol Control Beyond the Clinic: New York City's Trans Fat Restriction," Annals of Internal Medicine 151, no. 2 (2009):129-134; S. Y. Angell et al., "Change in Trans Fatty Acid Content of Fast-Food Purchases Associated With New York City's Restaurant Regulation: A Pre-Post Study," Annals of Internal Medicine 157, no. 2 (2012): 81-86.

25. N. L. Benowitz and J. E. Henningfield, "Establishing a Nicotine Threshold for Addiction - The Implications for Tobacco Regulation," New England Journal of Medicine 331, no. 2 (1994): 123-25.

26. G. Thomson et al., "Ending Appreciable Tobacco Use in a Nation: Using a Sinking Lid on Supply," Tobacco Control 19, no. 5 (2010): 431-35.

27. D. Khoo et al., "Phasing-out Tobacco: Proposal to Deny Access to Tobacco for Those Born from 2000," Tobacco Control 19, no. 5 (2010): 355-60.

28. S. Sugarman, "Performance-Based Regulation: Enterprise Responsibility for Reducing Death, Injury, and Disease Caused by Consumer Products," Journal of Health Politics, Policy and Law 34, no. 6 (2009): 1035-1077.

29. World Health Organization, Global Status Report on Noncommunicable Diseases 2010 (Geneva: WHO, 2011).
30.R. S. Magnusson, "What's Law Got to Do With It? Part 2: Legal Strategies for Healthier Nutrition and Obesity Prevention," Australia and New Zealand Health Policy June 5 (2008): 1-17.

31. J. M. Samet and H. L. Wipfli, "Globe Still in Grip of Addiction," Nature 463, no. 7284 (2010): 1020-1021.

32. A. T. Kenyon, "Internet Content Regulation and the World Health Organization Framework Convention on Tobacco Control," Scripted 6, no. 2 (2009): 341-353; L. Joosens et al., "The Impact of Eliminating the Global Illicit Cigarette Trade on Health and Revenue," Addiction 105, no. 9 (2010): 1640-1649.

33.J. Collin, "Global Health, Equity, and the WHO Framework Convention on Tobacco Control," Global Health Promotion 17, no. 1 (suppl.) (2010): 73-75.

34. World Health Organization, Global Status Report on Alcohol and Health (Geneva: WHO, 2011).

35. S. Casswell and T. Thamarangsi, "Reducing Harm from Alcohol: Call to Action," Lancet 373, no. 9682 (2009): 2247-2257.

36. B. Samb et al., "Prevention and Management of Chronic Disease: A Litmus Test for Health-Systems Strengthening in LowIncome and Middle-Income Countries," Lancet 376, no. 9754 (2010): 1785-1797.

37. World Health Organization, "Parties to the WHO Framework Convention on Tobacco Control," available at <http://www. who.int/fctc/signatories_parties/en/index.html> (last visited February 22, 2013).

38. World Health Organization (WHO), "Global Strategy for the Prevention and Control of Noncommunicable Diseases," World Health Assembly Resolution 53.14, available at < http://www. who.int/nmh/publications/wha_resolution53_14/en/index. html> (last visited February 22, 2013); WHO, "Global Strategy on Diet, Physical Activity and Health," World Health Assembly Resolution 57.17, available $a t<\mathrm{http} / /$ www.who.int/dietphysicalactivity/strategy/eb11344/en/index.html> (last visited February 22, 2013); WHO, Global Strategy to Reduce the Harmful Use of Alcohol, World Health Resolution 63.13, available at <http://www.who.int/substance_abuse/msbalcstragegy.pdf> (last visited February 22, 2013); WHO, "NCDnet - Global Noncommunicable Disease Network," available at <http://www. who.int/ncdnet/en/> (last visited February 22, 2013).

39. World Heart Federation, "Global Alliance for the Prevention of Obesity and Related Chronic Disease," available at < http:// www.world-heart-federation.org > (last visited February 22, 2013).

40. United Nations General Assembly, Political Declaration of the High-Level Meeting of the General Assembly on the Prevention and Control of Non-Communicable Diseases, DRAFT RESOLUTION SUBMITTED BY THE PRESIDENT OF THE GENERAL ASSEMBLY (September 16, 2011).

41. UN Special Rapporteur on the Right to Food, "UN Food Expert: Chance to Crack Down on Bad Diets Must not be Missed," available at <www.srfood.org > (last visited February $22,2013)$.

42. L. O. Gostin, "A Framework Convention on Global Health: Health for All, Justice for All," JAMA 307, no. 19 (2012): 2087-2092.

43. K. G. Del Ponte, "Formulating Customary International Law: An Examination of the WHO International Code of Marketing of Breast Milk Substitutes," Boston College International and Comparative Law Review 5, no. 2 (1982): 377-403.

44. See, for example, D. Sridhar, "Health Policy: Regulate Alcohol for Global Health," Nature 482, no. 7385 (2012): 302.

45. K. W. Abbott and D. Snidal, "Hard and Soft Law in International Governance," International Organization 54, no. 3 (2000): 421-456.

46. World Health Organization, Global Health Risks: Mortality and Burden of Disease Attributable to Selected Major Risks (Geneva: WHO, 2009).

47. C. Hawkes and K. Buse, "Public Health Sector and Food Industry Interaction: It's Time to Clarify the Term 'Partnership' and Be Honest About Underlying Interests," European Journal of Public Health 21, no. 4 (2011): 400-401. 
48. M. Caraher and G. Cowburn, "Taxing Food: Implications for Public Health Nutrition," Public Health Nutrition 8, no. 8 (2005): 1242-1249.

49.A. M. Brandt, The Cigarette Century: The Rise, Fall, and Deadly Persistence of the Product that Defined America (New York: Basic Books, 2007): at chapter 6 .
50.C. Blouin, "Global Responses to Chronic Diseases: What Lessons Can Political Science Offer," Administrative Sciences 2, no. 1 (2012): 120-134.

51. R. H. Thaler and C. R. Sunstein, Nudge (New Haven: Yale University Press, 2008). 
Copyright of Journal of Law, Medicine \& Ethics is the property of Wiley-Blackwell and its content may not be copied or emailed to multiple sites or posted to a listserv without the copyright holder's express written permission. However, users may print, download, or email articles for individual use. 